Sharif University of Technology
Scientia Iranica

\title{
Dynamic negawatt demand response resource modeling and prioritizing in power markets
}

\author{
A. Abdollahi ${ }^{a, c}$, N. Pour-Moallem ${ }^{\text {b,c }}$, and A. Abdollahi ${ }^{\text {,** }}$ \\ a. Department of Economics, Shahid Bahonar University of Kerman, Kerman, Iran. \\ b. Faculty of Engineering, Imam Khomeini International University of Qazvin, Iran. \\ c. Shakhes Pajouh Research Institute, Isfahan, Iran. \\ d. Department of Engineering, Shahid Bahonar University, Kerman, Iran.
}

Received 12 April 2016; received in revised form 4 April 2017; accepted 3 July 2017

\section{KEYWORDS}

Customers' benefit function;

Dynamic demand response;

Entropy method;

Load economic model; TOPSIS.

\begin{abstract}
In recent years, integrated use of demand- and supply-side resources has been performed by electric utilities, because of their potential attractiveness at both operational and economic levels. Demand Response Resources (DRRs) can be used as demand side options, which are the consequence of implementing Demand Response Programs (DRPs). DRPs comprise the actions taken by end-use customers to reduce their electricity consumption in response to electricity market's high prices and/or reliability problems on the electricity network. In this paper, a dynamic economic model of DRPs is derived based upon the concept of flexible elasticity of demand and the customer benefit function. Precise modeling of these virtual negawatt resources helps system operators to investigate the impact of responsive loads on power system studies. This paper also aims to prioritize multifarious DRPs by means of Technique for Order Preference by Similarity to Ideal Solution (TOPSIS) and entropy methods. Performance of the proposed model is investigated through numerical studies using a standard IEEE test system.
\end{abstract}

(C) 2020 Sharif University of Technology. All rights reserved.

\section{Introduction}

In the strategic plan of International Energy Agency (IEA) in 2008-2012 years, demand-side activities were introduced as the first choice in all energy policy decisions because of the respective potential benefits at both operational and economic levels [1]. Cost and emission reduction, the decrease of overseas fuel dependency, an increase in power system reliability, and an increase in revenues are some of the benefits via implementing Demand-Side Management (DSM)

\footnotetext{
*. Corresponding author.

E-mail addresses: abdollahi.ali100@gmail.com (A. Abdollahi);dnpm_eu@yahoo.com (N. Pour-Moallem); a.abdollahi@uk.ac.ir (A.Abdollahi)
}

programs [1-3]. There are three types of demand-side management measures based on the overall purpose of the Load Management (LM) program:

1. Environmental-driven measure: It achieves environmental and/or social goals by reducing energy usage and preventing polluted units, leading to increased energy efficiency and/or reduced greenhouse gas emissions [1];

2. Network-driven measure: It deals with challenges in the electricity network by reducing demands in ways that maintain the system reliability in the immediate term and defer the need for network augmentation over the longer term [3];

3. Economy/market-driven measure: It provides short-term responses to electricity market conditions to reduce the overall costs of energy supply, 
increase the reserve margin, and mitigate the price volatility [4].

Under deregulation, the scope of LM programs has considerably expanded to include Demand Response Programs (DRPs) [5]. In the Federal Energy Regulatory Commission (FERC) report [5], DRPs are divided into different categories: Time-Based Rate Programs (TBRPs), Incentive-Based Programs (IBPs), and Market-Based Programs (MBPs). A set of DRPs has been introduced as a negawat Demand Response Resources (DRRs). The concept of "negawatt" can be considered as a theoretical amount of energy saved by reducing consumption [6]. In DRPs, the customer signs a contract with the Independent system Operator (ISO) or the local utility to reduce the demands when requested [7]. By participating in DRPs, customers benefit particularly from the incentives provided by the ISO or local utility and the decrease of electricity bill [7]. DRPs are currently operational in many ISOs around the world [5]. Detailed explanations on DRPs are given in Section 2. In order to assess the impact of DRPs on power system studies, multifarious models have been developed in recent years. Economic models of responsive loads based on the concept of constant price elasticity have been addressed in references [812]. Schweppe et al. developed the concept of spot pricing of electricity to evaluate variable costs of electric energy on an hourly basis and proposed three responsive load models: linear, potential, and exponential demand functions [13]. A customers' response to the optimal real time prices has been modeled in [14] for the electricity applying multifarious mathematical load models. An optimization model was proposed to adjust the hourly load level of a given consumer in response to hourly electricity prices [15]. Another study utilizes ramping up/down rates to model variations in the customer load. An approval function based on the acceptable energy costs for different clusters of customers was presented in [16]. Moreover, the customer's behavior versus the offered fixed prices for monthly bilateral contracts by applying a type of market share function was proposed [17]. Aleázar-Ortega et al. [18] employed analytical and technical approaches to validating the impact of DRPs. Customer Baseline Load (CBL) which focuses on administrative and contractual approaches was applied to DRPs modeling [19]. Moreover, the impact of Demand Response (DR) through optimization methods was presented in [15]; however, an intelligent approach, such as multi-agent based and fuzzy logic method, was used to model demand responses [20,21]. Chen et al. [22] developed two markets for designing DRPs to match power supply and demand. DR models based on participation information of DRRs, suggested in [22], can be useful for evaluating DR resources' values. Kirschen showed how this model could be taken into consideration when scheduling generation and setting the price of electricity in a pool-based electricity market [23]. Market clearing programs were discussed in $[24,25]$, taking their economic benefits into account. A linear economic model of responsive loads was derived and used for multifarious studies in [26-32]. In [26-32], the elasticity of demand was considered as a fixed value for different values of incentive and penalty, which cannot precisely represent the customers' behavior. Therefore, in this paper, extracting a dynamic economic model of responsive loads was suggested based on the concepts of "flexible elasticity of demand" and "customer benefit function". Indeed, under a smart grid environment, the short-term elasticity of demand can be suggested [33]. Therefore, introducing the flexible elasticity as a consequence of smart electricity grids causes a more precise modeling of DRPs; hence, the decreasing rate of consumption coincides with the ISO's aim of implementing demand response programs. The proposed model is called dynamic, because the elasticity of demand should be appraised for each of DRPs based on the values of incentive, penalty, and the electricity price. The proposed dynamic model can be utilized to analyze the impact of DRPs on load profile characteristics. The entropy method as well as Technique for Order Preference by Similarity to Ideal Solution (TOPSIS) method have been also applied together to provide an opportunity for the decision-maker (i.e., ISO) to select the program with the highest priority from his point of view. TOPSIS is a method of compensatory aggregation that compares a set of alternatives by identifying weights for each criterion, normalizing scores for each criterion, and calculating the geometric distance between each alternative and the ideal alternative, which is the best score in each criterion [34]. This provides a more realistic form of modeling than non-compensatory methods, including or excluding alternative solutions based on hard cut-offs [34]. Herein, the goal of ISO is to select the most effective DRPs that promote the load profile characteristics/attributes, simultaneously. The proposed model is applied to the load curve of a standard IEEE ten-unit test system. The rest of the paper is organized as follows. Section 2 provides a brief background of DRPs. The problem formulation is explained in detail in Section 3. Section 4 conducts the numerical simulations. Finally, concluding remarks are drawn in Section 5.

\section{A glance at demand response programs}

DRPs can be classified as a set of Independent System Operator-based (ISO) programs that allow end users to provide interruptible load as a commodity in the electricity market. DRPs can be classified 
according to how load changes are brought about. In recent researches, DRPs have been divided into different categories: Time-Based Rate Programs (TBRPs), Incentive-Based Programs (IBPs), and Market-Based Programs (MBPs) [5]. Each of these categories consists of several programs as follows. TBRPs category includes several programs, such as Real-Time Pricing (RTP), Critical-Peak Pricing (CPP), and Time-Of-Use (TOU) tariffs, which give customers time-varying rates that reflect the value and cost of electricity in different time periods [5]. If the price differentials between hours or time periods are significant, customers can respond to the price structure with significant changes in energy use, thus reducing their electricity bills if they adjust the timing of their electricity usage to take advantage of lower-priced periods and/or avoid consuming when prices are higher [5]. IBPs include Direct Load Control (DLC), Interruptible/Curtailable service (I/C), Emergency Demand Response Program (EDRP), and Capacity Market Program (CAP) [5]. These programs give customers load reduction incentives that are separated from, or additional to, their retail electricity rate, which may be fixed (based on average costs) or timevarying [5]. DLC and EDRP are voluntary programs, and if customers do not curtail consumption, they are not penalized. I/C and CAP are mandatory programs, and enrolled customers are subject to penalties if they do not curtail when directed. Market-based programs include Demand Bidding (DB) and Ancillary Service (A/S) programs [5]. The DB program encourages customers to provide load reductions at a price at which they are willing to curtail, or to specify how much load they would be willing to curtail at posted prices. A/S programs allow customers to bid load curtailments in electricity markets as operating reserves. DRPs can be either a measure, a resource, or both in power system planning and operation phases with different timescales [26]. Short-term DR measures, such as DLC, can be used as fast-response resources for enhancing voltage control and improving power quality $[35,36]$. Long-term DR programs, such as those based on longterm contracts with customers, can be incorporated in the operational planning problems $[5,35]$. The focus of this paper is merely on EDRP and TOU programs. The time scale of EDRP and TOU programs is dayahead scheduling and more [5]. Detailed explanations on DRPs can be found in [35].

\section{Problem formulation}

\subsection{Development of responsive load dynamic economic model}

After restructuring the power system, the electricity is considered as a commodity in the state of a service. In the economy literature, the two most commonly used mathematical functions for representing a downward sloping price $(\Pi)$ versus demand $(D)$ are the linear $\left(D(t)=-a_{t} \Pi(t)+b_{t}\right)$ and the iso-elastic $(D(t)=$ $\left.a_{t} \Pi(t) b^{t}\right)$ models [31]. Since both of these functions are introduced in numerous standard economics textbooks, typically one of the two is selected when a demand curve is needed. It should be noted that along with price, the factors that mostly affect the demand for a commodity or service include consumer incomes and desires [31]. Shifts and movements in the demand curve are discussed as follows. Originally, the demand curve is depicted in Figure 1(a). When the demand curve shifts to the left (Figure 1(b)), people wish to buy smaller quantities of the commodity at each price. A leftward shift of the demand curve is a decrease in demand. Conversely, when the demand curve shifts to the right (Figure 1(c)), people wish to buy larger quantities of the commodity at each price. A rightward shift represents an increase in demand. A change in the commodity's own price only causes a movement along the demand curve, depicted in Figure 1(d).

In this paper, the linear function of demand curve (i.e., $\left.D(t)=-a_{t} \Pi(t)+b_{t}-z(t) f(A)\right)$ is suggested, where $f(A)$ represents the shift function of demand curve and $z(t)$ is assigned as follows:

$$
z(t)=\left\{\begin{aligned}
+1 & \text { Figure } 2(\mathrm{~b}), \text { for IBPs } \\
& \forall t \in\{\text { peak period }\} \\
0 \quad & \text { Figure } 2(\mathrm{~d}), \text { for TBRPs } \\
& \forall t \in\{\text { peak, off peak \& valley periods }\} \\
-1 & \text { Figure } 2(\mathrm{c}), \text { for IBPs } \\
& \forall t \in\{\text { off peak \& valley periods }\}
\end{aligned}\right.
$$

1. Elasticity of demand: Elasticity is defined as the demand sensitivity with respect to the price [37]:

$$
E(t, t)=\frac{\Pi(t)}{D(t)} \frac{\partial D(t)}{\partial \Pi(t)} .
$$

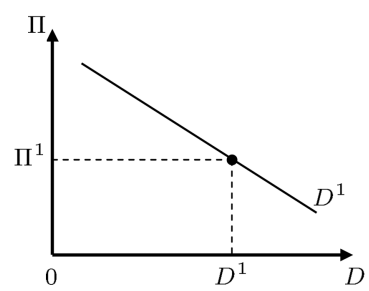

(a)

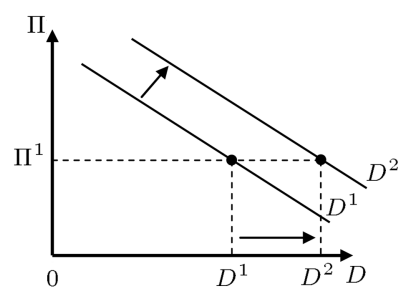

(c)

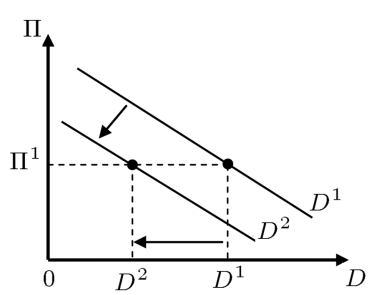

(b)

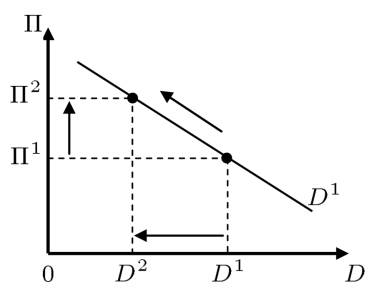

(d)
Figure 1. Shifts in demand curve; change in demand. 
Using the aforementioned function of demand curve (i.e., $\left.D(t)=-a_{t} I I(t)+b_{t}-z(t) f(A)\right)$, the selfelasticity of demand can be represented as follows:

$$
E(t, t)=\frac{-a_{t} \Pi(t)}{-a_{t} \Pi(t)+b_{t}-z(t) \cdot f(A)} .
$$

It should be mentioned that the demand elasticity is always measured at a spot price. In other words, even though the slope of the linear structure of the demand curve is constant, the demand elasticities are not the same at different prices and may increase by decreasing the demand. According to Eq. (2), the demand elasticity of the $t$-th period versus the $j$ th period, i.e., cross-elasticity, can be defined as follows [37]:

$$
E(t, j)=\frac{\Pi(j)}{D(t)} \frac{\partial D(t)}{\partial \Pi(j)} .
$$

In order to extract the formulation for the crosselasticity of demand, the following procedure is proposed. Suppose that the electricity market offers the electricity power at three different prices such as $\Pi(t), \Pi(j)$, and $\Pi(k)$. When the electricity price is equal to $\Pi(t) \$ / \mathrm{MWh}, \Pi(j) \$ / \mathrm{MWh}$, and $\Pi(k) \$ / \mathrm{MWh}$, a customer consumes $D(t), D(j)$, and $D(k)$ megawatt hours of electricity, respectively. Herein, it is assumed that each customer has the ability to spend $I(\$)$ for consuming electricity. The preceding explanations can be expressed mathematically as follows:

$$
\Pi(t) D(t)+\Pi(j) D(j)+\Pi(k) D(k)=I .
$$

Considering the linear structure for the demand curve, $\Pi(t), D(j)$, and $D(k)$ are defined as follows:

$$
\begin{aligned}
& \Pi(t)=\frac{-D(t)+b_{t}-z(t) f(A)}{a_{t}}, \\
& D(j)=-a_{t} \Pi(j)+b_{t}-z(j) f(A), \\
& D(k)=-a_{t} \Pi(k)+b_{t}-z(k) f(A) .
\end{aligned}
$$

Substitution of Eqs. (6)-(8) into Eq. (5) and differentiating $D(t)$ with respect to $\Pi(j)$ yield Eq. (9) as shown in Box I, which can be extended for a market with " $N$ " different electricity prices.

Therefore, according to Eq. (4), the crosselasticity of demand (the $t$ th period versus the $j$ th period) can be represented as in Eq. (10) as shown in Box II.

2. Responsive load dynamic economic model: Suppose that, by implementing DRPs, the customer changes his demand from $D_{0}(t)$ (initial value) to $D(t)$. Therefore, the demand change will be [29]:

$$
\Delta D(t)=D(t)-D_{0}(t) .
$$

If $A(t)(\$)$ is paid as an incentive to the customer at the $t$ th hour for each MWh load reduction, the total incentive for participating in IBPs will be as follows [29]:

$$
p(\Delta D(t))=A(t)\left[D_{0}(t)-D(t)\right] \quad \forall t .
$$

If the customer enrolled in DRPs does not commit to his obligations according to the contract, he will

$$
\begin{aligned}
& \frac{\partial D(t)}{\partial \Pi(j)} \\
& \quad=\frac{-2 a_{t}^{2} \Pi(j)+a_{t} b_{t}-a_{t} f(A) z(j)}{\left\{\left(b_{t}-z(t) f(A) a_{t}\right)^{2}+4\left[-a_{t}^{2}\left(\Pi(j)^{2}+\Pi(k)^{2}\right)+a_{t} b_{t}(\Pi(j)+\Pi(k))-a_{t} I-a_{t} f(A)(z(j) \Pi(j)+z(k) \Pi(k))\right]\right\}^{1 / 2}}
\end{aligned}
$$

$$
\begin{aligned}
E(t, j)= & \frac{-2 a_{t}^{2} \Pi(j)+a_{t} b_{t}-a_{t} f(A) z(j)}{\left\{\left(b_{t}-z(t) f(A) a_{t}\right)^{2}+4\left[-a_{t} \cdot I+\sum_{\substack{\xi=1 \\
\xi \neq t}}^{N}-a_{t}^{2} \Pi(\xi)^{2}+a_{t} b_{t} \Pi(\xi)-a_{t} f(A) z(\xi) \Pi(\xi)\right]\right\}^{1 / 2}} \\
& \times \frac{\Pi(j)}{-a_{t} \Pi(t)+b_{t}-z(t) f(A)} .
\end{aligned}
$$


be faced with penalty. If the contract level at the $t$ th hour and the penalty in the same period are denoted by $I C(t)$ and pen $(t)$, respectively, then the total penalty will be calculated as follows [29]:

$$
P E N(\Delta D(t))=\operatorname{pen}(t)[I C(t)-|\Delta D(t)|] .
$$

If $B(D(t))$ is the income of customer during the $t$ th hour from the use of $D(t)$ (MWh) of electricity, then the customer's benefit, $S(D(t))$, for the $t$ th hour will be as follows [29]:

$$
\begin{aligned}
S(D(t))= & B(D(t))-D(t) \Pi(t)+p(\Delta D(t)) \\
& -P E N(\Delta D(t)) .
\end{aligned}
$$

In Eq. (14), $B(D(t))$ is the customers' benefit function, which is the quadratic function as follows [13]:

$$
\begin{aligned}
B(D(t))= & B_{0}(t)+\Pi_{0}(t)\left[D(t)-D_{0}(t)\right] \\
& \left\{1+\frac{D(t)-D_{0}(t)}{2 E(t, t) D_{0}(t)}\right\} .
\end{aligned}
$$

Using Eqs. (12), (13), and (15), the graph of $S(D(t))$ is similar to an open down parabola. Hence, according to the classical optimization rules, to maximize the customer's benefit, $\partial S / \partial D(t)$ should be equal to zero. Solving $\partial S / \partial D(t)$ for $\partial B(D(t)) / \partial D(t)$ yields as follows [29]:

$$
\frac{\partial B(D(t))}{\partial D(t)}=\Pi(t)+A(t)+\text { pen }(t) \quad \forall D(t) \geq 0
$$

Differentiating Eq. (15) with respect to $D(t)$ and substituting the result into Eq. (16), the customer's consumption will be as follows [29]:

$D(t)=D_{0}(t)\left\{1+E(t, t) \frac{\Pi(t)-\Pi_{0}(t)+A(t)+\text { pen }(t)}{\Pi_{0}(t)}\right\}$.

Substitution of Eq. (3) into Eq. (17) yields:

$$
\begin{aligned}
D(t)= & D_{0}(t)\left\{1-\frac{a_{t} \Pi(t)}{\Pi_{0}(t)}\right. \\
& \left.\times \frac{\Pi(t)-\Pi_{0}(t)+A(t)+\text { pen }(t)}{-a_{t} \Pi(t)+b_{t}-z(t) f(A)}\right\} .
\end{aligned}
$$

Eq. (18) represents the behavior of some loads with sensitivity just in a single period. Such loads are not able to move from one period to another (e.g., illuminating loads) and can be only on or off. On the other hand, some loads can be transferred from the peak period to the off-peak or low periods (e.g., process loads). Such behavior is called multi-period sensitivity and can be evaluated using "cross-elasticity of demand" [38]. Similar to the procedure of acquiring Eq. (17), the multi-period load economic model can be expressed as follows:

$$
\begin{aligned}
D(t)= & D_{0}(t)\left\{1+\sum_{\substack{j=1 \\
j \neq t}}^{24} E(t, j)\right. \\
& \left.\frac{\left[\Pi(j)-\Pi_{0}(j)+A(j)+\operatorname{pen}(j)\right]}{\Pi_{0}(j)}\right\} .
\end{aligned}
$$

Eq. (19) can be extended according to the definition of cross-elasticity in Eq. (10) as shown in Box III.

By combining Eqs. (18) and (20) and considering coefficient " $\eta$ " as the potential of DRPs implementation, the responsive load dynamic economic model will be presented as in Eq. (21) as shown in Box IV.

\subsection{Procedure of DRPs sorting}

One of the responsibilities of a decision-maker (i.e., ISO) is setting rules for selecting and prioritizing DRPs [38]. The goal of this section is to select the most effective DRPs that promote the load profile characteristics/attributes, simultaneously. Since the criteria of building P\&D (Planning and Design) evaluation have diverse significance and meanings, it cannot be assumed that each evaluation criterion is

$$
D(t)=D_{0}(t)\left\{\sum_{\substack{j=1 \\ t \neq j}}^{24} \frac{\left[-2 a_{t}^{2} \Pi(j)^{2}+\Pi(j)\left(a_{t} b_{t}-a_{t} f(A) z(j)\right)\right]\left[\Pi(j)-\Pi_{0}(j)+A(j)+\text { pen }(j)\right]}{\left.\left.\left(b_{t}-z(t) f(A) a_{t}\right)^{2}+4\left[-a_{t} . I+\sum_{\substack{\xi=1 \\ \xi \neq t}}^{N}-a_{t}^{2} \Pi(\xi)_{0}(j)+b_{t} \Pi_{0}(j)-z(t) f(A) \Pi_{0}(j)\right]^{-1} \Pi(\xi)-a_{t} f(A) z(\xi) \Pi(\xi)\right]\right\}}\right\} .
$$


$D(t)=\eta D_{0}(t)\left\{\begin{array}{c}1-\frac{a_{t} \Pi(t)}{\Pi_{0}(t)} \times \frac{\Pi(t)-\Pi_{0}(t)+A(t)+\operatorname{pen}(t)}{-a_{t} \Pi(t)+b_{t}-z(t) \cdot f(A)}+\cdots \\ {\left[-2 a_{t}^{2} \Pi(j)^{2}+\Pi(j)\left(a_{t} b_{t}-a_{t} f(A) z(j)\right)\right]\left[\Pi(j)-\Pi_{0}(j)+A(j)+\operatorname{pen}(j)\right]} \\ \left.\sum_{\substack{j=1 \\ t \neq j}}^{24} \frac{\left[-a_{t} \Pi(t) \Pi_{0}(j)+b_{t} \Pi_{0}(j)-z(t) f(A) \Pi_{0}(j)\right]^{-1}}{\left.\left(b_{t}-z(t) f(A) a_{t}\right)^{2}+4\left[-a_{t} \cdot I+\sum_{\substack{\xi=1 \\ \xi \neq t}}^{N}-a_{t}^{2} \Pi(\xi)^{2}+a_{t} b_{t} \Pi(\xi)-a_{t} f(A) z(\xi) \Pi(\xi)\right]\right\}^{1 / 2}}\right\} .(21)\end{array}\right\}$

Box IV

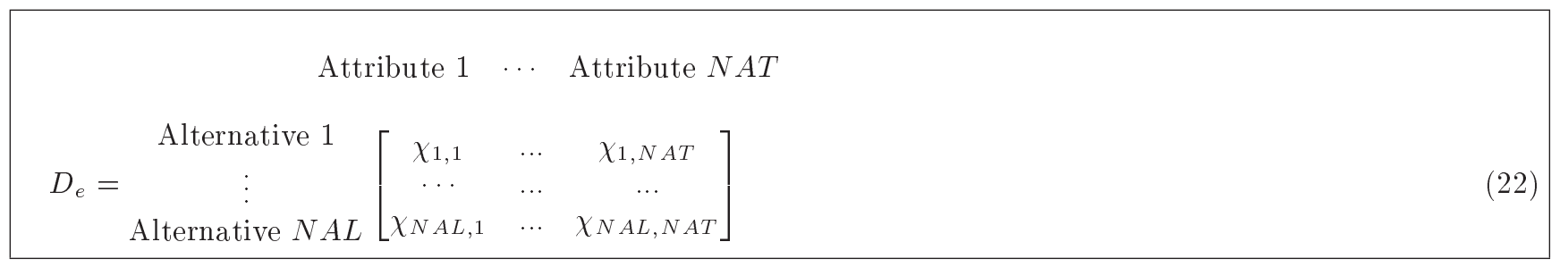

Box V

of equal importance [34]. Evaluating the best plan is a complex and wide-ranging problem, requiring the most inclusive and flexible method [34]. Herein, the attributes are weighted by means of the entropy method [39]. Entropy is a criterion in the information theory that explains the uncertainty in a discrete distribution function $\left(P_{l}\right)$ that can be summarized as follows. Consider a decision matrix, $D_{e}$, as Eq. (22) shown in Box V, where $\chi_{l k}$ is the performance of the $l$ th alternative regarding the $k$-th attribute [34]. Each element of the decision matrix, i.e., Eq. (22), can be normalized as follows:

$$
P_{l k}=\frac{\chi_{l k}}{\sum_{k=1}^{N A L} \chi_{l k}} .
$$

Thus, weighting each attribute, $W_{k}$, can be calculated by:

$$
W_{k}=\frac{1+(\ln N A L)^{-1} \cdot \sum_{l=1}^{N A L}\left[P_{l} \times \ln P_{l}\right]_{k}}{\sum_{k=1}^{N A T}\left\{1+(\ln N A L)^{-1} \cdot \sum_{l=1}^{N A L}\left[P_{l} \times \ln P_{l}\right]_{k}\right\}} .
$$

If the decision-maker has a prior consideration/ knowledge about the importance factor of attribute $\left(\lambda_{k}\right)$, then the weights are improved as follows:

$$
I W_{k}=\frac{\lambda_{k} \times W_{k}}{\sum_{k=1}^{N A T} \lambda_{k} \times W_{k}} .
$$

In Eq. (25), lower weights suggests that the impact of the attribute is similar for all of the alternatives and its importance is negligible for the decision.

In this step, ISO sorts the DRPs (alternatives) by means of TOPSIS method. TOPSIS as a multicriteria decision analysis method is a sub-discipline of operations research that explicitly evaluates multiple conflicting criteria in decision-making [34]. Herein, TOPSIS is based on the concept that the chosen alternative should have the shortest geometric distance from the positive ideal solution and the longest geometric distance from the negative ideal solution [34]. It is a method of compensatory aggregation that compares a set of alternatives by identifying weights for each criterion, normalizing scores for each criterion, and calculating the geometric distance between each alternative and the ideal alternative, which is the best score in each criterion. An assumption of TOPSIS is that the criteria are monotonically increasing or decreasing. Normalization is usually required as the parameters or criteria are often of incongruous dimensions in multicriteria problems. Compensatory methods, such as TOPSIS, allow trade-offs between criteria, where a poor result in one criterion can be negated by a good result in another criterion. This provides a more realistic form of modeling than non-compensatory methods, including or excluding alternative solutions based on hard cut-offs. In this paper, the goal of ISO is to select the most effective DRPs that promote the load profile characteristics/attributes, simultaneously $[34,40]$. The optimization procedure of TOPSIS method can be presented as follows [40]: 


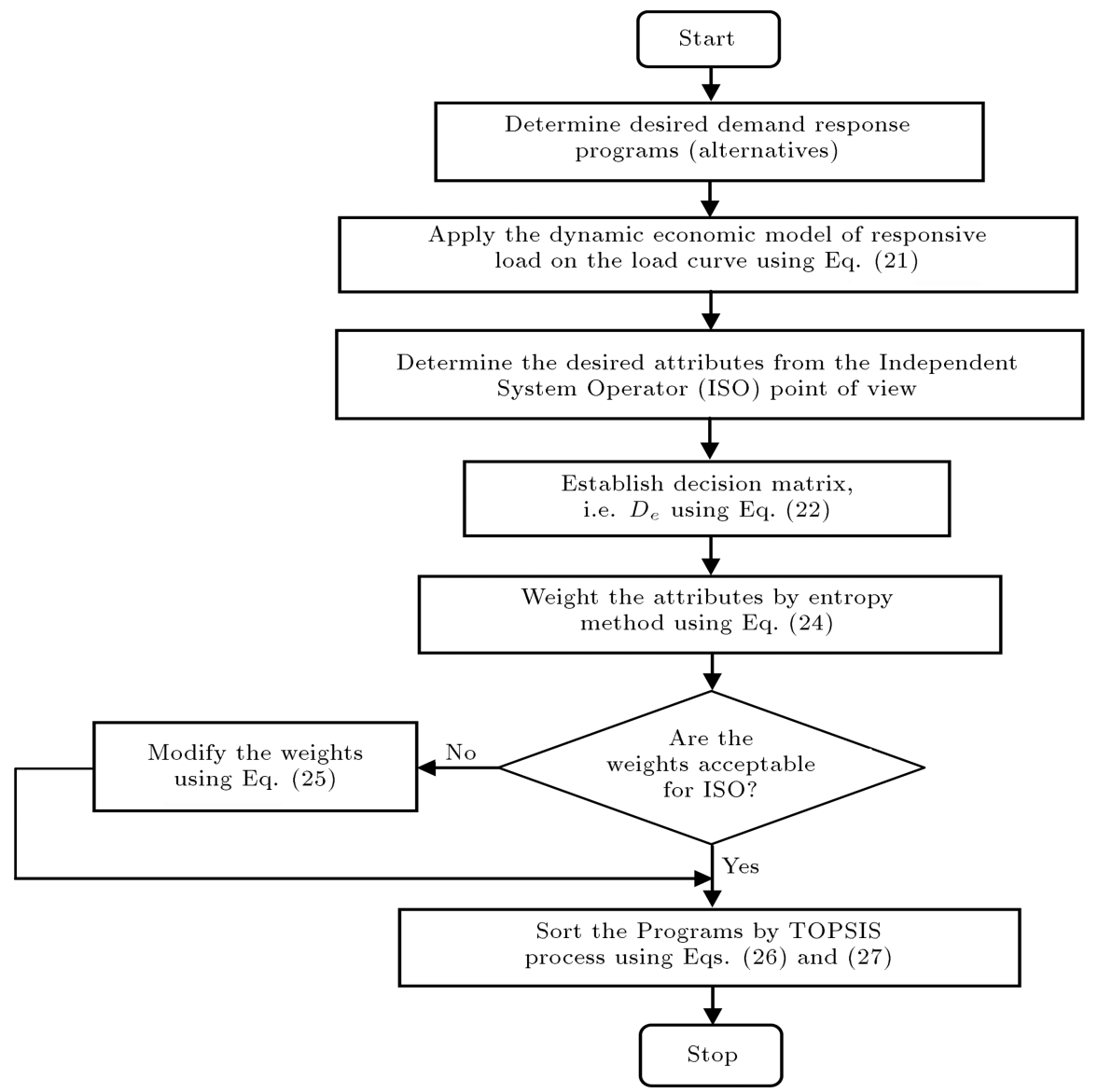

Figure 2. Flowchart of prioritizing demand response programs.

i. Calculate weighted normalized $D_{e}$ matrix as follows:

$$
V_{l k}=W_{k} \times \frac{\chi_{l k}}{\sqrt{\sum_{l=1}^{N A L} \chi_{l k}^{2}}} .
$$

ii. Find the ideal and anti-ideal solutions. The ideal solution, $v_{k}^{+}$, is the maximum value for the positive criterion and the minimum value for the negative criterion in each column. Similarly, the antiideal solution, $v_{k}^{-}$, is the minimum and maximum values for the positive and negative criteria in each column, respectively;

iii. The mean distance between each alternative and anti-ideal solution can be calculated as follows:

$$
C_{l}=\frac{\sqrt{\sum_{k=1}^{N A T}\left(v_{l k}-v_{k}^{-}\right)^{2}}}{\sqrt{\sum_{k=1}^{N A T}\left(v_{l k}-v_{k}^{+}\right)^{2}}+\sqrt{\sum_{k=1}^{N A T}\left(v_{l k}-v_{k}^{-}\right)^{2}}}
$$

$$
0 \leq C_{l} \leq 1
$$

Finally, the alternatives are sorted according to $C_{l}$ value. The higher $C_{l}$ coefficient is, the more effective the program (alternative) will be. Figure 2 depicts the aforementioned hierarchy for the demand response portfolio-sorting algorithm.

\section{Simulation results and discussion}

In this section, the standard IEEE ten-unit test system has been used for simulation studies. Figure 3 represents the aforementioned load curve that is divided into three different periods, namely valley

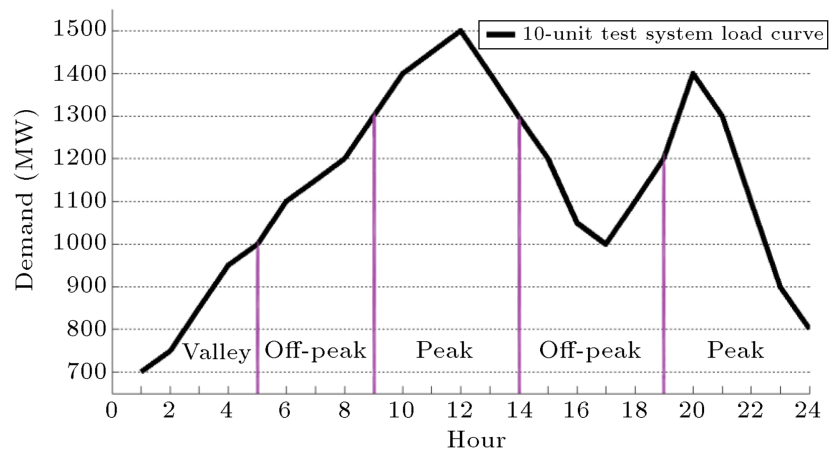

Figure 3. Ten-unit test system load curve. 
period (00:00 am-5:00 am), off-peak period (5:00 am9:00 am and 14:00 pm-19:00 pm), and peak period (9:00 am-14:00 pm and 19:00 pm-24:00 pm) [26]. The implementation potential of DRPs is considered 0.2 and 0.4 , meaning that the total signed contracts for participating customers in the programs are equal to $20 \%$ and $40 \%$ of the total load, respectively.

In this study, the constant coefficients of the linear demand curve, i.e., " $a_{t}$ " and " $b_{t}$ ", are assumed 7 and 1300, respectively [41]. Several DRPs have been introduced as indicated in Table 1 which are the combination of TBRPs and IBPs. Herein, the initial value of electricity price and $f(A)$ are assumed equal to $20 \$ /$ MWh and $\left\{0.1 b_{t} \times A / A_{\max }\right\}$, respectively, where $A_{\max }$ is considered equal to $10 \$ / \mathrm{MWh}$, as shown in Table 1.

For each of the aforementioned programs, the demand elasticity is calculated using Eqs. (3) and (10) and listed in Table 2. It can be concluded that increasing the values of incentive and electricity price is directly parallel to the elasticity of demand. Implementation of dynamic DRPs provides the means for customers to decrease or shift their consumption from peak period to the valley or off-peak periods.

\subsection{Studying the effect of proposed dynamic $D R$ model on the load curve}

This section discusses the results obtained through numerical studies from both "economical" and "load profile characteristics" viewpoints. The DR incentive value as an economic index is calculated for each of DRPs. Furthermore, several technical indices, namely peak reduction, electrical energy consumption, load factor, and peak to valley distance, are evaluated for

Table 1. Statement of scenarios.

\begin{tabular}{|c|c|c|c|c|c|}
\hline $\begin{array}{c}\text { Programs } \\
(I=2000 \$)\end{array}$ & $\begin{array}{c}\text { Program } \\
\text { no. }\end{array}$ & $\begin{array}{c}\text { Scenario } \\
\text { no. }\end{array}$ & $\eta$ & $\begin{array}{c}\Pi(t) \\
(\$ / M W h)\end{array}$ & $\begin{array}{c}\text { Incentive } \\
\text { value } \\
(\$ / \mathrm{MWh})\end{array}$ \\
\hline \multirow{7}{*}{ 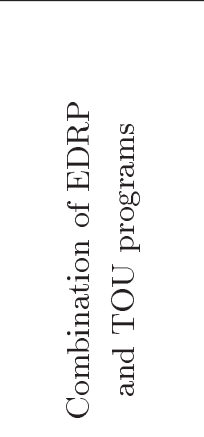 } & \multirow{2}{*}{1} & 1 & 0.2 & \multirow{2}{*}{22.5} & \multirow{3}{*}{4} \\
\hline & & 2 & 0.4 & & \\
\hline & 2 & $\begin{array}{l}3 \\
4 \\
\end{array}$ & $\begin{array}{l}0.2 \\
0.4 \\
\end{array}$ & 27.5 & \\
\hline & \multirow{2}{*}{3} & 5 & 0.2 & \multirow{2}{*}{22.5} & \multirow{4}{*}{10} \\
\hline & & 6 & 0.4 & & \\
\hline & 4 & 7 & 0.2 & \multirow{2}{*}{27.5} & \\
\hline & 4 & 8 & 0.4 & & \\
\hline
\end{tabular}

Table 2. Calculated elasticity of demand for different DRPs.

\begin{tabular}{|c|c|c|c|c|c|c|c|c|c|c|}
\hline \multirow{4}{*}{ 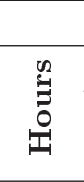 } & \multicolumn{10}{|c|}{ Elasticity of programs 1 and $2(A=4 \$ / M W h)$} \\
\hline & \multicolumn{2}{|c|}{$1-5$} & \multicolumn{2}{|c|}{ 6-9 } & \multicolumn{2}{|c|}{ 10-14 } & \multicolumn{2}{|c|}{ 15-19 } & \multicolumn{2}{|c|}{ 20-24 } \\
\hline & Program & Program & Program & Program & Program & Program & Program & Program & Program & Program \\
\hline & 1 & 2 & 1 & 2 & 1 & 2 & 1 & 2 & 1 & 2 \\
\hline $1-5$ & -0.1207 & -0.1207 & 0.0321 & 0.0309 & 0.032 & 0.0348 & 0.0321 & 0.0309 & 0.032 & 0.0348 \\
\hline $6-9$ & 0.0321 & 0.0309 & -0.1207 & -0.1207 & 0.032 & 0.0348 & 0.0321 & 0.0309 & 0.032 & 0.0348 \\
\hline $10-14$ & 0.0354 & 0.0358 & 0.0354 & 0.0358 & -0.1480 & -0.1870 & 0.0354 & 0.0358 & 0.0354 & 0.0404 \\
\hline $15-19$ & 0.0321 & 0.0309 & 0.0321 & 0.0309 & 0.032 & 0.0348 & -0.1207 & -0.1207 & 0.032 & 0.0348 \\
\hline \multirow[t]{2}{*}{$20-24$} & 0.0354 & 0.0358 & 0.0354 & 0.0358 & 0.0354 & 0.0404 & 0.0354 & 0.0358 & -0.1480 & -0.1870 \\
\hline & \multicolumn{10}{|c|}{ Elasticity of programs 3 and $4(A=10 \$ / M W h)$} \\
\hline \multirow{3}{*}{ 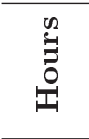 } & \multicolumn{2}{|c|}{$1-5$} & \multicolumn{2}{|c|}{$6-9$} & \multicolumn{2}{|c|}{$10-14$} & \multicolumn{2}{|c|}{ 15-19 } & \multicolumn{2}{|c|}{ 20-24 } \\
\hline & Program & Program & Program & Program & Program & Program & Program & Program & Program & Program \\
\hline & 3 & 4 & 3 & 4 & 3 & 4 & 3 & 4 & 3 & 4 \\
\hline $1-5$ & -0.1207 & -0.1207 & 0.0329 & 0.0329 & 0.0287 & 0.0287 & 0.0329 & 0.0329 & 0.0287 & 0.0287 \\
\hline $6-9$ & 0.0329 & 0.0329 & -0.1207 & -0.1207 & 0.0287 & 0.0287 & 0.0329 & 0.0329 & 0.0287 & 0.0287 \\
\hline $10-14$ & 0.0406 & 0.0414 & 0.0406 & 0.0414 & -0.1662 & -0.2110 & 0.0406 & 0.0414 & 0.0354 & 0.0402 \\
\hline $15-19$ & 0.0329 & 0.0329 & 0.0329 & 0.0329 & 0.0287 & 0.0287 & -0.1207 & -0.1207 & 0.0287 & 0.0287 \\
\hline $20-24$ & 0.0406 & 0.0414 & 0.0406 & 0.0414 & 0.0354 & 0.0402 & 0.0406 & 0.0414 & -0.1662 & -0.2110 \\
\hline
\end{tabular}


Table 3. Economical and technical comparison of DRPs.

\begin{tabular}{|c|c|c|c|c|c|c|}
\hline \multirow{2}{*}{$\begin{array}{c}\text { Program } \\
\text { no. }\end{array}$} & \multicolumn{2}{|c|}{ DR incentive value $(\$)$} & \multicolumn{2}{|c|}{ Peak (MW) } & \multicolumn{2}{|c|}{ Peak reduction (\%) } \\
\hline & $\eta=0.2$ & $\eta=0.4$ & $\eta=0.2$ & $\eta=0.4$ & $\eta=0.2$ & $\eta=0.4$ \\
\hline Initial load & - & - & 1,500 & 1,500 & - & - \\
\hline 1 & $2,828.52$ & $5,657.04$ & $1,415.4$ & 1,369 & -5.63 & -8.73 \\
\hline 2 & 4,896 & $9,792.01$ & $1,353.7$ & $1,382.8$ & -9.75 & -7.81 \\
\hline 3 & $19,291.2$ & $38,582.4$ & $1,375.0$ & 1,450 & -8.33 & -3.32 \\
\hline 4 & $28,652.8$ & $57,304.5$ & $1,375.8$ & 1,451 & -8.28 & -3.22 \\
\hline
\end{tabular}

Table 4. Technical comparison of DRPs.

\begin{tabular}{|c|c|c|c|c|c|c|}
\hline \multirow{2}{*}{$\begin{array}{c}\text { Program } \\
\text { no. }\end{array}$} & \multicolumn{2}{|c|}{ Energy consumption (MWh) } & \multicolumn{2}{|c|}{ Load factor (\%) } & \multicolumn{2}{|c|}{ Peak to valley (MW) } \\
\hline & $\eta=0.2$ & $\eta=0.4$ & $\eta=0.2$ & $\eta=0.4$ & $\eta=0.2$ & $\eta=0.4$ \\
\hline Initial load & 27,100 & 27,100 & 75.27 & 75.27 & 800 & 800 \\
\hline 1 & $26,741.5$ & $26,383.1$ & 78.71 & 80.29 & 699.6 & 659.2 \\
\hline 2 & 26,228 & 25,356 & 80.73 & 76.41 & 639.4 & 738.8 \\
\hline 3 & $25,972.9$ & $24,845.9$ & 78.71 & 71.39 & 697.9 & 895.9 \\
\hline 4 & $24,970.7$ & $22,841.4$ & 75.62 & 65.56 & 758.5 & 1,016 \\
\hline
\end{tabular}

each program. Tables 3 and 4 compare the performance of the proposed DR model using the above-mentioned economical and technical indices.

The first rows in Tables 3 and 4 present the "base case" with actual load curve (Figure 3 ), where no DRP is implemented. In this case, as shown in Table 4, the load factor is equal to $75.27 \%$ which will be increased by implementing several DRPs of Table 1 . The energy consumption is $27,100 \mathrm{MWh}$ that is considerably more than the other programs. The load curve will be improved after implementing different DRPs as follows.

Program 1: Now, it is assumed that ISO pays $4 \$ / \mathrm{MWh}$ as an incentive for load reduction, and the electricity price for peak period is considered equal to $22.5 \$ /$ MWh. As seen in Tables 3 and 4 , in Program 1 , the maximum peak reduction $(8.73 \%)$, the maximum increase in load factor $(6.67 \%)$, and the minimum distance between peak and valley (659.15 MW) are achieved when $\eta=0.4$, in comparison with the base case. According to Table 3, for this case, the minimum DR incentive value is $2,828.52 \$$ for $\eta=0.2$, as compared with other DRPs;

Program 2: In this case, a maximum load factor $(80.73 \%)$ is achieved for $\eta=0.2$ in comparison with the base case. As indicated in Table 3, by decreasing customers' participation level, the load reduction value will increase and stand at the allowable level (9.75\% for $\eta=0.2)$. The maximum distance between peak and valley $(738.86 \mathrm{MW})$ is achieved when $\eta=$ 0.4 ; by decreasing customers' participation level, this technical parameter will have descending behavior;

Program 3: In the third program, it is assumed that $10 \$ / \mathrm{MWh}$ is an incentive and $22.5 \$ / \mathrm{MWh}$ is the price for implementing DRPs. By applying the proposed model to the initial load curve, maximum peak reduction is obtained $(-8.33 \%)$ when $\eta=0.2$. Herein, when $\eta=0.4$, the value of load factor is decreased $(5.16 \%)$ and the distance between peak and valley is increased by $11.98 \%$ for $\eta=0.4$, as compared with the base case;

Program 4: In this case, the value of load factor is decreased which is in the direct relation with the values of price and incentive. According to Table 4, the distance between peak and valley is increased after implementing this program for $\eta=0.4$. In Program 4, the value of load factor is decreased at least $12.90 \%$ for $\eta=0.4$.

In the subsequent section, we will discuss the importance of customers' participation level, values of incentive, and electricity price for each of DRPs from the ISO perspective in detail.

\subsection{Prioritization of DRPs}

To improve the load profile characteristics as well as customer's benefit, the following attributes are considered: "peak reduction", "energy consumption", "load factor", "distance between peak to valley", and "DR incentive value". Accordingly, decision matrix $D_{e}$ is established using Eq. (22) with the results shown in Tables 3 and 4 . The decision matrix represents the performance of each program for each attribute. Then, the attributes are weighted by the entropy method. The calculated weights of the attributes are shown in Table 5. Since ISO has the primary responsibility of maintaining security of the system, the weights of attributes should be acceptable from its point of view; 


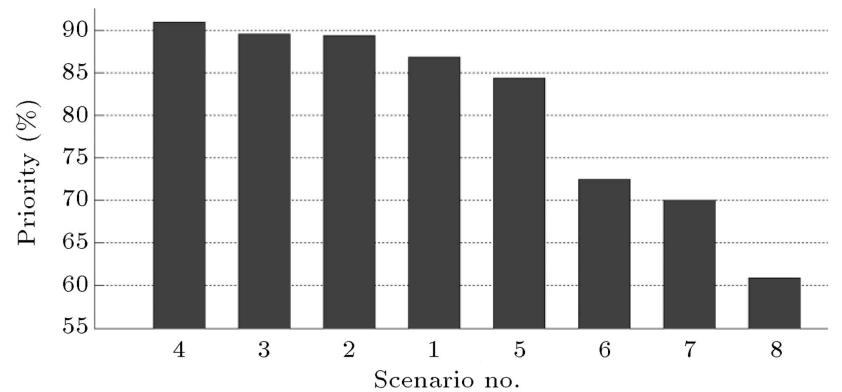

Figure 4. Prioritizing of scenarios from ISO perspective using TOPSIS method.

Table 5. Weights of attributes.

\begin{tabular}{lc}
\hline \multicolumn{1}{c}{ Attribute } & Weight \\
\hline Peak reduction & 0.1446 \\
Energy consumption & 0.0024 \\
Load factor & 0.0046 \\
Peak to valley & 0.0267 \\
DR incentive value & 0.8217 \\
\hline
\end{tabular}

Table 6. Improved weights of attributes.

\begin{tabular}{lc}
\hline \multicolumn{1}{c}{ Attribute } & Improved weight \\
\hline Peak reduction & 0.3274 \\
Energy consumption & 0.0018 \\
Load factor & 0.0104 \\
Peak to valley & 0.0403 \\
DR incentive value & 0.6201 \\
\hline
\end{tabular}

otherwise, ISO can modify the weights based on its decision. For example, peak load reduction increases the reserve capacity, which will result in increasing the system security margin .

Hence, ISO may consider the importance factor of attributes as follows:

$$
\begin{gathered}
\lambda_{N A T}=\{0.3,0.1,0.3,0.2,0.1\} \\
\forall N A T=1,2,3,4,5 .
\end{gathered}
$$

Based on the above importance factors, the improved weights of attributes are obtained using Eq. (25) as presented in Table 6 .

Now, by using the TOPSIS method, the priorities of DRPs can be calculated as indicated in Figure 4. According to Figure 4, by implementing Scenario 4 with the highest priority, ISO will obtain the desired load profile characteristics and achieve relative satisfaction of costumers. Investigation of the above results reveals that, for various policies, different improved weights of attributes will result in multifarious priorities of DRPs. In practice, when some restrictions exist to implement a certain program with higher priority, ISO can choose another program with lower priority.

\section{Conclusion}

In this paper, DRPs as one of the important infrastructures of smart grid technologies were studied. This paper described a study in which a dynamic model was suggested to demonstrate and quantify the economic impact of price elasticity of demand in DRPs. Herein, the importance of emergency DRPs and TOU programs was investigated. Therefore, based upon flexible elasticity of demand as well as customer benefit function, a dynamic economic model of responsive loads was derived for DRPs. This model can be utilized for the purpose of improving load profile characteristics as well as satisfaction of customers. ISO could prioritize multifarious DRPs and would choose the best program with the highest priority considering its perspectives. Prioritizing approach of DRPs was presented based on multi-attribute decision-making techniques including entropy and TOPSIS methods. The applicability of the proposed structure was illustrated using a standard IEEE ten-unit test system. Future research is required to develop more accurate models of DRPs considering load uncertainty as well as market clearing regarding virtual DRRs.

\section{Nomenclature}

$A(t) \quad$ Incentive of the demand response program at the $t$-th hour for each MWh load reduction

$a_{t}, b_{t} \quad$ Coefficients of demand curve

$B(D(t)) \quad$ Customer's income at the $t$ th hour after implementing DRPs

$B_{0}(t) \quad$ Customer's income when the demand is at nominal value $\left(D_{0}(t)\right)$

$D(t) \quad$ Power demand at the $t$ th hour after implementing DRPs

$D_{e} \quad$ Decision matrix

$D_{0}(t) \quad$ Power demand at the $t$ th hour

$E(t, j) \quad$ Cross-elasticity

$E(t, t) \quad$ Self-elasticity

$f(A) \quad$ Demand curve shift function, which is assumed as a function of incentive Customer' funds for consuming electricity

$I C(t) \quad$ Incentive-based programs contract level

$j \quad j$ th period

$k \quad k$ th period

ln Natural logarithm function

$N \quad$ Number of different electricity prices in the market

$N A L \quad$ Number of alternatives 


\begin{tabular}{|c|c|}
\hline$N A T$ & Number of attributes \\
\hline$p(\Delta D(t))$ & $\begin{array}{l}\text { Total incentive for customers' } \\
\text { participation in DRPs at } t \text { th hour }\end{array}$ \\
\hline $\operatorname{pen}(t)$ & Penalty at the $t$ th hour \\
\hline$S(D(t))$ & $\begin{array}{l}\text { Customer's benefit from implementing } \\
\text { DRPs at the } t \text { th hour }\end{array}$ \\
\hline$V_{l k}$ & Weighted normalized decision matrix \\
\hline$v_{k}^{+}$ & Ideal solution \\
\hline$v_{k}^{-}$ & Anti-ideal solution \\
\hline$W$ & Weighting of attributes \\
\hline$\chi_{l k}$ & $\begin{array}{l}\text { Performance of the } l \text { th alternative } \\
\text { regarding the } k \text { th attribute }\end{array}$ \\
\hline$z(t)$ & $\begin{array}{l}\text { Binary value which is equal to } 1 \text { for } \\
\text { implementing IBPs at the } t \text { th time } \\
\text { interval; otherwise, it is equal to } 0\end{array}$ \\
\hline$\Pi(t)$ & $\begin{array}{l}\text { Secondary/virtual electricity price of } \\
\text { an hour for implementing TBRPs }\end{array}$ \\
\hline$\Pi_{0}(t)$ & $\begin{array}{l}\text { Initial electricity price of an hour } \\
\text { before implementing DRPs }\end{array}$ \\
\hline$\eta$ & Potential of implementing DRPs \\
\hline$\lambda_{k}$ & Decision-maker's importance factor \\
\hline
\end{tabular}

\section{References}

1. IEA, Strategic Plan for the IEA Demand-Side Management Program 2008-2012, [Online]. Available: www.iea.org; [accessed 2015-11-12].

2. Göransson, L., Goop, J., Unger, T., Odenberger, M., and Johnsson, F. "Linkages between demandside management and congestion in the European electricity transmission system", Energy, 69, pp. 860872 (2014).

3. Parvania, M. and Fotuhi-Firuzabad, M. "Demand response scheduling by stochastic SCUC", IEEE Transactions on Smart Grid, 1(1), pp. 89-98 (2010).

4. Rahmani-andebili, M. "Modeling nonlinear incentivebased and price-based demand response programs and implementing on real power markets", Electric Power Systems Research, 132, pp. 115-124 (2016).

5. FERC, Staff Report, Assessment of demand response and advanced metering [Online]. Available: www.FERC.gov (August 2006).

6. http://en.wikipedia.org/wiki/Negawatt_ power [accessed 2015-10-27].

7. Rahmani-andebili, M. "Nonlinear demand response programs for residential customers with nonlinear behavioral models", Energy and Buildings, 119, pp. 352362 (2016).

8. Bompard, E., Ma, Y., Napoli, R., and Abrate, G. "The demand elasticity impacts on the strategic bidding behavior of the electricity producers", IEEE Transactions on Power Systems, 22(1), pp. 188-197 (2007).
9. Goel, L., Wu, Q., and Wang, P. "Reliability enhancement and nodal price volatility reduction of restructured power systems with stochastic demand side load shift", IEEE Power Engineering Society General Meeting Conference, Florida, USA, pp. 1-8 (2007).

10. Yu, N. and Yu, J.1. "Optimal TOU decision considering demand response model", International Conference on Power System Technology, Chongqing, China, pp. 1-5 (2006).

11. Goel, L., Qiuwei, W., and Peng, W. "Reliability enhancement of a deregulated power system considering demand response", IEEE Power Engineering Society General Meeting Conference, Montreal, Que., Canada, pp. 1-6 (2006).

12. Su, C.L. and Kirschen, D. "Quantifying the effect of demand response on electricity markets", IEEE Transactions on Power Systems, 24(3), pp. 1199-1207 (2009).

13. Schweppe, F.C., Caramanis, M.C., Tabors, R.D., and Bohn, R.E. "Spot pricing of electricity", In Power Electronics and Power Systems, Springer Science \& Business Media (2013).

14. Yousefi, S., Moghaddam, M.P., and Majd, V.J. "Optimal real time pricing in an agent-based retail market using a comprehensive demand response model", Energy, 36(9), pp. 5716-5727 (2011).

15. Conejo, A.J., Morales, M., and Baringo, L. "Realtime demand response model", IEEE Transactions on Smart Grid, 1(3), pp. 236-242 (2010).

16. Mahmoudi-Kohan, N., Moghaddam, M.P., and Sheikh-El-Eslami, M.K. "An annual framework for clustering-based pricing for an electricity retailer", Electric Power Systems Research, 80(9), pp. 1042-1048 (2010).

17. Hatami, A.R., Seifi, H., and Sheikh-El-Eslami, M.K. "Optimal selling price and energy procurement strategies for a retailer in an electricity market", Electric Power Systems Research, 79(1), pp. 246-254 (2009).

18. Alcázar-Ortega, M., Escrivá-Escrivá, G., and SeguraHeras, I. "Methodology for validating technical tools to assess customer demand response: application to a commercial customer", Energy Conversion and Management, 52(2), pp. 1507-1511 (2011).

19. Chao, H. "Demand response in wholesale electricity markets: the choice of customer baseline", Journal of Regulatory Economics, 39(1), pp. 68-88 (2011).

20. Ferreira, R.S., Barroso, L.A., and Carvalho, M.M. "Demand response models with correlated price data: A robust optimization approach", Appllied Energy, 96, pp.133-149 (2012).

21. Lecocq, S. and Robin, J.M. "Estimating demand response with panel data", Empirical Economics, 31(4), pp. 1043-1060 (2006).

22. Chen, L., Li, N., Low, S.H., and Doyle, J.C. "Two market models for demand response in power networks", First IEEE International Conference on Smart Grid Communications, Gaithersburg, USA, pp.397402 (2010). 
23. Kirschen, D.S., Strbac, G., Cumperayot, P., and Mendes, D.P. "Factoring the elasticity of demand in electricity prices", IEEE Transactions on Power Systems, 15(2), pp. 612-617 (2000).

24. Khodaei, A., Shahidehpour, M., and Bahramirad, S. "SCUC with hourly demand response considering intertemporal load characteristics", IEEE Transactions on Smart Grid, 2(3), pp. 564-571 (2011).

25. Aghaei, J. and Alizadeh, M.I. "Robust n-k contingency constrained unit commitment with ancillary service demand response program", IET Generation, Transmission and Distribution, 8(12), pp. 1928-1936 (2014).

26. Abdollahi, A., Moghaddam, M.P., Rashidinejad, M., and Sheikh-el-Eslami, M.K. "Investigation of economic and environmental-driven demand response measures incorporating UC", IEEE Transactions on Smart Grid, 3(1), pp. 12-25 (2012).

27. Aalami, H., Yousefi, G.R., and Moghadam, M.P. "A MADM-based support system for DR programs", 43th International Universities Power Engineering Conference, Padova, Italy, pp. 1-7 (2008).

28. Aalami, H., Yousefi, G.R., and Moghadam, M.P. "Demand response model considering EDRP and TOU programs", IEEE/PES Transmission and Distribution Conference and Exposition, Bogota, Colombia, pp. 1-6 (2008).

29. Aalami, H.A., Moghaddam, M.P., and Yousefi, G.R. "Demand response modeling considering interruptible/curtailable loads and capacity market programs", Applied Energy, 87(1), pp. 243-250 (2010).

30. Aalami, H.A., Moghaddam, M.P., and Yousefi, G.R. "Modeling and prioritizing demand response programs in power markets", Electric Power Systems Research, 80(4), pp. 426-435 (2010).

31. Moghaddam, M.P., Abdollahi, A., and Rashidinejad, M. "Flexible demand response programs modeling in competitive electricity markets", Applied Energy, 88(9), pp. 3257-3269 (2011).

32. Aghaei, J. and Alizadeh, M.I. "Critical peak pricing with load control demand response program in unit commitment problem", IET Generation, Transmission and Distribution, 7(7), pp. 681-690 (2013).

33. Thimmapuram, P.R. and Kim, J. "Consumers' price elasticity of demand modeling with economic effects on electricity markets using an agent-based model", IEEE Transactions on Smart Grid, 4(1), pp. 390-397 (2013).

34. Tzeng, G.H. and Huang, J.J., Multiple Attribute Decision Making Methods and Applications, Taylor \& Francis Group, LLC (2011).

35. Aghaei, J. and Alizadeh, M.I. "Demand response in smart electricity grids equipped with renewable energy sources: a review", Renewable and Sustainable Energy Reviews, 18, pp. 64-72 (2013).

36. Mozafari, B., Amraee, T., Ranjbar, A.M., and Mirjafari, M. "Particle swarm optimization method for optimal reactive power procurement considering voltage stability", Scientia Iranica, 14(6), pp. 534-545 (2007).
37. Kirschen, D. and Strbac, G., Fundamentals of Power System Economics, John Wiley \& Sons, Ltd (2004).

38. Tabandeh, A., Abdollahi, A., and Rashidinejad, M. "Reliability constrained congestion management with uncertain negawatt demand response firms considering repairable advanced metering infrastructures", Energy, 104, pp. 213-228 (2016).

39. Nigim, K., Munier, N., and Green, J. "Pre-feasibility MCDM tools to aid communities in prioritizing local viable renewable energy sources", Renewable Energy, 29(11), pp. 1775-1791 (2004).

40. Shanian, A. and Savadogo, O. "TOPSIS multiplecriteria decision support analysis for material selection of metallic bipolar plates for polymer electrolyte fuel cell", Journal of Power Sources, 159(2), pp. 1095-1104 (2006).

41. Barforoushi, T., Moghaddam, M.P., Javidi, M.H., and Sheikh-El-Eslami, M.K. "Evaluation of regulatory impacts on dynamic behavior of investments in electricity markets: a new hybrid dp/game framework", IEEE Transactions on Power Systems, 25(4), pp. 1978-1986 (2010).

\section{Biographies}

Ali Abdollahi received BSc degree in Civil Engineering from Azad university of Kerman, Iran in 2007. He received the MSc degree at the Road and Transportation Engineering Department at Shahid Chamran university of Ahvaz, Iran in 2009. He is currently pursuing $\mathrm{PhD}$ degree in Economics at Shahid Bahonar University of Kerman, Iran.

Nasser Pour-Moallem received BSc degree in Civil Engineering from Isfahan University of Technology, Isfahan, Iran in 1989, MSc degree in Transportation and Traffic Engineering from the Hokkaido University, Sapporo-Japan in 1993, and PhD degree in Transportation and Traffic Engineering from the Hokkaido University, Sapporo-Japan in 1997. He is currently an Assistant Professor in Department of Transportation and Road and Transportation Planning, Imam Khomeini International University of Qazvin, Iran.

Amir Abdollahi received his BSc degree in Electrical Engineering from Shahid Bahonar University, Kerman, Iran in 2007 and MSc degree in Electrical Engineering from Sharif University of Technology, Tehran, Iran in 2009. He received his $\mathrm{PhD}$ in Electrical Engineering from Tarbiat Modarres University (TMU), Tehran, Iran in 2012. He is currently an Associate Professor at the Department of the Engineering, Shahid Bahonar University of Kerman, Iran. His research interests include demand-side management, optimization, planning and economics in smart grids. 